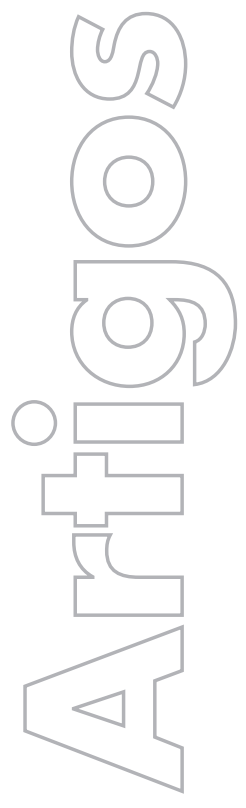

revista

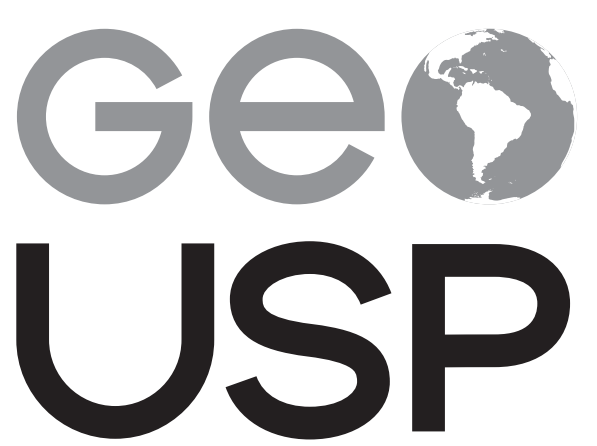

espaço e tempo

Volume $22 \cdot n^{\circ} 3$ (2018)

\section{A acumulação primitiva do capital e o discreto charme da geografia burguesa}

Paulo Roberto Teixeira de Godoy

Unesp

p. $559-571$

Como citar este artigo:

GODOY, P. R. T. A acumulação primitiva do capital e o discreto charme da geografia burguesa. Geousp - Espaço e Tempo (Online), v. 22, n. 3, p. 559-571, dez. 2018. ISSN 2179-0892.

Disponível em: <https://www.revistas.usp.br/geousp/article/view/119886>. doi: http://dx.doi.org/10.11606/issn.21790892.geousp.2018.119886.

\section{(C) $(1) \circledast$}

Este artigo está licenciado sob a Creative Commons Attribution 4.0 License. 


\title{
A acumulação primitiva do capital e o discreto charme da geografia burguesa ${ }^{1}$
}

\begin{abstract}
Resumo
O texto apresenta notas e apontamentos para uma análise histórica e dialética da produção do espaço geográfico como mercadoria específica do modo capitalista de produção. As formas de expropriação e de sucessivas separações entre as condições objetivas de produção e os produtores diretos constituem as bases categoriais da universalização da propriedade privada da terra e da geografia histórica da valorização capitalista no espaço. $\bigcirc$ território como dimensão concreta das práticas e das representações sociais orientadas pela lógica de valorização do capital e das formas ideológicas de dominação política é o pressuposto inicial da interpretação do processo de transformação do território em capital fictício.
\end{abstract}

Palavras-chave: Acumulação. Valorização. Espaço.

\section{The primitive Accumulation of Capital and the Discrete Charm of the Bourgeois Geography ${ }^{2}$}

\begin{abstract}
The text presents notes and remarks on a historical and dialectical analysis of the production of the geographical space as a specific commodity of the capitalist mode of production. The forms of expropriation and successive separations between the objective conditions of production and the direct producers are the categorical basis of the universalization of private ownership of land and historical geography of the capitalist valorization in space. The territory is the concrete dimension of the practices and social representations guided by the logic of capital appreciation and the ideological forms of political domination. These are the initial assumptions for the interpretation of the transformation process of the territory in fictitious capital.
\end{abstract}

Keywords: Accumulation. Valuation. Space. 


\section{Introdução}

O período que se estende de 1870 a 1930 foi marcado sobretudo pelas sucessivas crises de superacumulação nas economias europeias e, ao mesmo tempo, pela expansão do capital global mediante a conversão de capital excedente em fundos de renda, aquisição de terras e sistema de créditos em países periféricos e em territórios coloniais, isto é, pela expansão do imperialismo. Os imperativos da acumulação ampliada avançavam em forma de ferrovias, portos, imigrações, propriedade privada, trabalho assalariado, guerras etc. (Luxemburg, 1984).

A intensificação da valorização capitalista no espaço mediante a lógica de concentração e centralização do capital com tendências a urbanização, industrialização e substituição do trabalho escravo pelo trabalho assalariado transformou a periferia, particularmente a América Latina, num imenso mercado de fundos territoriais, de renda e mais-valor absoluto. A modernização do território como sinônimo da expansão da malha ferroviária e dos meios de comunicação (telégrafo etc.), dos investimentos na revitalização de portos, na geração de energia elétrica etc., consiste nas formas de circulação e reprodução do capital na dimensão orgânica de valorização do valor. A produção do espaço torna-se a condição concreta da produção. Como escreve Milton Santos (1992, p. 40), "são espaços de produção e de consumo", quando atingidos por "um novo patamar da divisão internacional do trabalho, todos os lugares dela participam, seja pela produção, seja pelo consumo".

Com a expansão e o desenvolvimento do capitalismo, uma nova estrutura espacial se constitui em um processo movido pelas próprias contradições internas do capital. "Para superar as barreiras espaciais e anular o espaço pelo tempo", diz Harvey (2005, p. 53), "criam-se estruturas espaciais, que, no fim, agem como barreiras contra a acumulação adicional [...]. Assim, [...] uma paisagem física, criada como valor de uso, acentuando a acumulação [...] numa escala expansível". Milton Santos chega à conclusão de que:

[... o uso direto do espaço, como suporte do processo produtivo e como meio de trabalho tecnicamente elaborado, leva a um nível mais alto que jamais a sua capacidade de transferir valor ao conjunto de instrumentos e meios de trabalho que nele têm base [...] a produção de valor começa antes mesmo que a mercadoria produzida na fábrica, no atelier ou no escritório esteja concluída. Estamos diante de um espaço-valor, mercadoria cuja aferição é função de sua prestabilidade ao processo produtivo e da parte que toma na realização do capital (1992, p. 61).

O cenário é definido, grosso modo, pela transição do capitalismo agrário para uma nova economia sediada na cidade, mas impulsionada pela produção industrial e agrícola, pelas finanças e pelo comércio, ou seja, uma tradução sumária das novas formas do movimento do capital na produção e na valorização do valor e, portanto, no estabelecimento de uma nova divisão social e territorial do trabalho e da formação de uma peculiar sociabilidade mediada pela produção de mercadorias com abrasiva expansão das relações sociais capitalistas em todas as dimensões da sociedade.

território, em construção contínua, constitui-se por esse processo de dois modos: de um lado, se apresenta como substrato físico, delimitado por fronteiras político-administrativas que configura a soberania do Estado nacional; por outro lado, como resultado concreto da 
violência e das relações sociais historicamente constituídas a partir do metabolismo trabalho e natureza, mediado pela reprodução do capital. Assim, a metamorfose que opera na constituição do território gera um "território fictício" sob a aura de "nacional" e, ao mesmo tempo, seu oposto contraditório, que é sua construção a partir de uma sucessão de separações e divisões que se estabelecem com a ordem objetiva da propriedade privada da terra, dos meios de produção e das formas de expropriação do trabalho e de acumulação de capitalista.

Embora distintos na aparência, a gênese histórica fora a mesma. $\bigcirc$ processo de colonização, iniciado no século XVI e que prossegue até os nossos dias sob o rótulo de "acumulação por espoliação" (acumulação primitiva), é revelador não só das ideologias que impregnam as práticas do poder político, mas também dos imperativos da acumulação capitalista no processo histórico de formação social e territorial. A noção de território nacional como produção histórica pressupõe, desse modo, um aparato simbólico e ideológico inerente ao embate dinâmico da luta de classes, mas que assume e re-assume a aparência de um todo homogêneo que constitui o "povo" ou a "nação". A base concreta dessas representações sociais é vista, neste artigo, a partir das relações contraditórias de produção capitalista e das formas específicas de sociabilidade reificada daí derivadas.

A análise que apresentamos avança para a geografia histórica da transição do capitalismo periférico. A interpretação histórica da espacialização do capital e suas expressões ideológicas no mundo do trabalho, reveladas em sua essência pela propriedade privada da terra e pelo trabalho assalariado, permite-nos situar a discussão acerca das relações entre território fictício e valorização capitalista no espaço sobre fundamentos teóricos, cuja magnitude alcança a realização da crítica em torno dos processos sociais e das formas espaciais que caracterizam a expansão das relações capitalistas no e do movimento de reprodução do valor e de suas formas de acumulação ampliada.

Para o desenvolvimento da análise acerca da valorização capitalista no espaço, torna-se necessário, segundo os nossos objetivos apresentar, de modo esquemático, a "transição do capital à propriedade privada" e "a transição da propriedade privada ao trabalho assalariado" como metodologia de interpretação da especificidade da propriedade capitalista da terra como fundamento seminal da renda da terra e da transformação do espaço em "território fictício".

\section{Acumulação primitiva e "acumulação por espoliação"}

Marx compara a acumulação primitiva do capital ao pecado original, por uma analogia entre a desventura de Adão com a maçã e, como por feitiço, surge o pecado no mundo. Da mesma maneira e "naturalmente", a sociedade se divide, de um lado, numa classe "laboriosa, inteligente e, sobretudo, dotada de aptidões administrativas" e, de outro, num bando de "folgazões" que se diverte noite e dia sem qualquer preocupação com o futuro. Certamente, esta prospera e acumula riquezas, enquanto aquela se vê desprovida de tudo. De fato, o pecado original condena o homem a "ganhar seu pão com o suor de seu rosto; mas a do pecado econômico preenche uma lamentável lacuna revelando-nos como e por que há homens que escapam a esta ordem do Senhor" (Marx, 1964, p. 11-12). Como escreve W. Benjamin (2013, p. 23) em $O$ capitalismo como religião, "no Ocidente, o capitalismo se desenvolveu como parasita do cristianismo [...] de tal forma que, no final das contas, sua história é essencialmente a história de seu parasita, ou seja, do capitalismo". 
Do mesmo modo como fazem os apóstolos da economia política burguesa em relação à origem do capital e da propriedade privada da terra, o faz também a teologia em relação ao pecado original; ambas têm natureza e gênese nebulosas, aparência sedutora, narcótica e colonizadora transcendental das representações humanas. Mas a "lamentável lacuna da ordem do Senhor" é, lógica e historicamente, preenchida pela necessidade intangivel da ordem do capital em seu movimento sublime e natural de autovalorização: condena os "folgazões" pecadores ao trabalho de Sísifo como única forma de se manter vivos e de pagar por suas heresias, enquanto os dotados de "aptidões administrativas" e fiéis aos desígnios do Senhor gozam de toda fé e riqueza material.

"Nos anais da história real", diz Marx (1964, p. 13), "o que sempre tem prevalecido é, ao contrário, a conquista, a dominação, a rapina à mão armada, o predomínio da força bruta". 0 processo histórico de separação do produtor direto de suas condições materiais de produção é o movimento seminal da chamada acumulação primitiva do capital. Em sentido amplo, pode-se afirmar que:

[...] a história da sociedade capitalista é a história da produção incessante da separação [...]. Separação entre trabalhador e os instrumentos de trabalho, entre as relações de produção e as forças produtivas, entre o trabalho e o produto do trabalho, [...] entre o trabalho manual e o trabalho intelectual, entre público e privado, [...] separação entre todas as esferas da vida social e suas representações (Chauí, 1984, p. 54).

As condições concretas de realização das relações capitalistas de produção estão nos processos de separação e de efetivação da propriedade privada, sobretudo, o pressuposto da propriedade privada da terra é a universalização do trabalho assalariado. Assim, é preciso produzir indivíduos socialmente determinados e cujo único "bem" seja sua própria força de trabaIho. A base de toda a formação do capital está na expropriação dos produtores diretos. Como diz Marx (1991, p. 100), "a riqueza sob a forma de dinheiro só poderá ser trocada pelas condições objetivas de trabalho, se estas tiverem sido separadas do próprio trabalho". Nas palavras de Rosa Luxemburg (1984, p. 32):

[...] na acumulação primitiva, ou seja, nos primórdios históricos do capitalismo na Europa, em fins da Idade Média, bem como pelo século XIX adentro, a encampação do pequeno estabelecimento agrícola pelo grande constitui, na Inglaterra e no continente, o meio mais importante para a transformação maciça dos meios de produção e da força de trabalho em capital. E até hoje essa mesma tarefa é levada em frente em escala bem maior, na política colonial, pelo capital dominante.

A análise empreendida por Marx acerca da gênese do capital e da propriedade privada, já prevista nos Grundrisse e nos planos iniciais de O capital, apresenta-se como ponto de partida para a compreensão do movimento geral do capital, sem o qual não haveria a possibilidade de interpretação de suas particularidades. Trata-se do estudo sobre a "transição do capital à propriedade da terra" e "da propriedade da terra ao trabalho assalariado" (Marx, $1858^{3}$ apud Rosdolsky, 2001, p. 45).

3 Carta de Marx a Engels escrita em 2 de abril de 1858, Briefwechsel, II, p. 383. 
$\bigcirc$ ponto de partida, o capital em sua origem, implica a existência do dinheiro, isto é, "a existência de riqueza em forma de dinheiro [...], portanto, não se origina da propriedade da terra (embora possa derivar dos arrendatários agrícolas [...] comerciantes de produtos agro-pecuários), nem das corporações mas da riqueza mercantil e usuária” (Marx, 1991, p. 101).

A conversão da riqueza monetária em capital é determinada pela existência da oferta de força de trabalho por trabalhadores "livres", despojados das condições objetivas de produção e submetidos a circunstâncias históricas distintas, senão na totalidade, mas necessariamente em parcialidade, dos precedentes modos de produção, permitindo "que o valor, existente como riqueza monetária, adquira, de um lado, as condições objetivas do trabalho para, do outro, lado, trocar o trabalho vivo [...] por dinheiro" (Marx, 1991, p. 103). Portanto, a "formação original do capital" não está na acumulação das condições objetivas de produção, mas na forma específica como o dinheiro estabelece a relação com o trabalho e com a produção do valor de troca daí resultante. Em suma, para se tornar efetivas e dominantes, as separações que caracterizam as relações entre trabalho e capital "terão de desenvolver-se não apenas localmente, mas em grande escala” (Marx, 1991, p. 102).

\section{A propriedade capitalista da terra}

A propriedade capitalista da terra consiste numa forma específica de propriedade, diferente das anteriores, mas contendo-as como condição originária. No capitalismo, a propriedade da terra apresenta-se, num primeiro momento, como antítese do capital, pois não consiste em "uma fonte da qual brote valor, [...] nem tampouco é uma fonte da qual brote mais-valia [...] Mas essa propriedade é uma fonte de renda [...] uma imposição para receber trabalho não pago" (Marx ${ }^{4}$ apud Rosdolsky, 2001, p. 45). A propriedade privada permite, então, ao seu proprietário se apropriar de mais-valor da qual não participa, necessariamente, de sua criação.

A geração da renda fundiária (monopolista, absoluta e diferencial 1 e 2) fora interpretada por Marx, nos Grundrisse, como o único caso em que o capital produz um valor distinto de si mesmo. Por isso, tal forma de propriedade privada da terra é específica do capitalismo, e sua existência universal implica necessariamente a destruição de todas as formas anteriores de propriedade da terra. Para obter essas condições relativas à terra e ao trabalho, "o capital não conhece outra solução senão a da violência, um método constante da acumulação capitalista no processo histórico, não apenas por ocasião de sua gênese, mas até mesmo hoje" (Luxemburg, 1984, p. 33). Contudo, de acordo com Marx, há uma "transição do capital à propriedade da terra". Essa transição deve ser analisada tanto dialética quanto historicamente. Do ponto de vista da dialética, os recursos naturais são apropriados pelo capital como condição de produção de mercadorias, portanto, como gerador de renda que pode ser incorporado no valor de troca.

Além da teoria da renda, Marx analisa a "transição da propriedade da terra ao trabalho assalariado", considera a propriedade da terra produto e antítese do capital e, ao mesmo tempo, geradora de renda em dinheiro, convertendo as atividades diretamente ligadas ao uso do solo em modalidades de produção capitalistas subordinadas às determinações da valorização do valor e, consequentemente, a sucessivas separações. "A transição [...] está implícita no fato de que a propriedade da terra é produto do capital" (Marx, 1964, p. 126).

4 MARX, K. Formações econômicas pré-capitalistas. Trad. João Maia. São Paulo: Paz e Terra, 1991. 
De acordo com Rosdolsky (2001, p. 48), o que Marx procura discutir é a própria estrutura de sua obra:

[...] o problema da ordem em que devem ser descritas as categorias do capital, da propriedade da terra e do trabalho assalariado que expressam a estrutura de classes da sociedade burguesa. A investigação das relações recíprocas entre essas categorias leva à seguinte resposta: como relação decisiva da sociedade burguesa, que em tudo penetra e a tudo domina, deve-se elaborar primeiramente a categorial do capital em sua forma pura, deixando de lado as formas que podem ser deduzidas das relações do próprio capital. Só então se pode tratar da moderna propriedade da terra, como criação do capital, como produto de sua influência sobre formas econômicas pré-capitalistas.

Vale ressaltar, com relação ao argumento de Rosdolsky, que os estudos de Marx acerca do movimento geral do capital, da gênese da propriedade privada da terra e da transição para o trabalho assalariado, que antecedem os Grundrisse, apresentam notas críticas à alienação do trabalho humano com a efetivação da propriedade privada e das formas de fetichismo da mercadoria e do dinheiro. Os Cadernos de Paris e manuscritos econômico-filosóficos de 1844 trazem reflexões essenciais para a construção do método de Marx na interpretação e na elaboração da crítica a economia burguesa.

Com a universalização da propriedade privada, pressuposto seminal do trabalho assalariado, e do dinheiro como equivalente geral de troca ("mediador externo"), estabelecem-se as determinações ontonegativas do valor e as formas sociais de alienação do homem. Por meio do dinheiro:

[...] o homem, em lugar de ser ele mesmo o mediador para o homem, experimenta a sua vontade, a sua atividade, a sua relação com os outros como uma potência independente de si mesmo e dos outros [...]. Este mediador é, por consequência, a essência da propriedade privada tornada exterior a ela mesma, expulsa dela mesma, tanto como é a mediação entre as produções humanas, mas uma mediação alienada, a atividade genérica do homem separada do homem (Marx, 2015, p. 201).

Abstraída sua concretude pela mediação do dinheiro, cujo sentido lógico do movimento é a própria valorização do valor, a sociabilidade humana torna-se a expressão negativa das relações humanas. Isso porque o intercâmbio, na concepção de Marx presente nos Cadernos, "não é um movimento social [...] não é uma relação humana, mas a relação abstrata da propriedade privada". O nexo invertido das relações de intercâmbio, mediado pelo dinheiro, aliena o homem do produto de seu trabalho e de si mesmo, produzindo relações reificadas sob a aparência de relações naturais de compra e venda. "É nesta transição histórica que vai arrastando o homem para seu estranhamento, que vai se constituindo o dinheiro como produto e não produto do homem" (Cotrim, 2011, p. 198).

As notas sobre a troca, o valor e o preço apontam a crítica incisiva de Marx acerca das relações sociais produzidas pelo intercâmbio da propriedade privada: 
O intercâmbio ou a troca é o ato social, o ato genérico, a comunidade, o comércio social e a integração dos homens no interior da propriedade privada - é, pois, o ato genérico exterior, alienado. Por isso, aparece como troca e, na verdade, é o contrário da relação social [...] Em lugar da sua unidade imediata consigo mesma, ela existe somente como uma relação a qualquer outra. Como equivalente, a sua existência não é mais a sua própria particularidade. Ela se converteu, pois, em valor, e diretamente em valor de troca. Sua existência como valor é uma determinação diferente da sua existência imediata, é exterior à sua natureza específica; é uma determinação alienada de si mesma, uma existência relativa da sua natureza (Marx, 2015, p. 211-212).

A propriedade privada constitui-se, desse modo, a condição fundante da alienação do homem e sua aparente transformação em coisa. $\bigcirc$ próprio trabalho torna-se coisa, "uma mercadoria e que progressivamente é concebido apenas sob o aspecto de um capital e não como atividade humana" (Marx, 2015, p. 224).

Terceiro manuscrito começa com a relação da propriedade privada e sua "essência subjetiva", o trabalho. $\bigcirc$ fato de a economia política reconhecer no trabalho a fonte de riquezas, não significa o reconhecimento da propriedade privada como "um estado exterior ao homem", o que faz dela (a economia política burguesa) um produto "do movimento da propriedade privada (é um movimento autônomo que se tornou para si na consciência, é a indústria moderna como sujeito) (als selbst), como produto da indústria moderna, que por sua vez acelera e enaltece a energia e o movimento dessa indústria, transformando-a numa força da consciência" (Marx, 1974, p. 9). A economia política torna-se a negação do homem, "o que antes era ser-exterior-a-si, exteriorização real do homem, converteu-se apenas no fato da exteriorização, em estranhamento" (Marx, 1974, p. 10).

○ constituir-se como "essência tensa da propriedade privada", negação da própria fruição do homem como ser genérico, o trabalho apresenta-se não somente alienado em relação ao produto e ao produtor direto, como gera no interior das relações humanas, as mesmas metamorfoses antitéticas das mercadorias. Para se realizar, o trabalho vivo, produtor de valor de uso, deve produzir seu oposto, o trabalho morto (trabalho abstrato), para que o valor assuma existência autônoma frente ao trabalho e, assim, o desvalorize na mesma proporção em que cria mais valor.

Com a teoria da renda da terra, ${ }^{5}$ Marx desvenda o enigma da propriedade privada como fonte de renda. Se a terra não é produto do trabalho humano, portanto, não contém valor. Mas, como condição de produção separada do produtor direto, tem preço e, com efeito, pode ser incluída nas relações de compra e venda. Como salienta Harvey (2013, p. 447-450), a partir do Livro III de O capital:

[...] se a terra for livremente comercializada, então ela se torna uma mercadoria de um tipo muito especial. Como a terra não é produto do trabalho, ela não pode ter um valor. A aquisição da terra "simplesmente assegura ao comprador

5 Marx definiu quatro formas de renda da terra: monopolista, absoluta, diferencial 1 e diferencial 2. Ver: MARX, K. O capital, Livro III; HARVEY, D. Os limites do capital (2013); Seção 11 - A teoria da renda. 
um direito de receber uma renda anual". Qualquer fluxo de renda (como uma renda anual) pode ser considerado como o juro sobre algum capital fictício, imaginário. Para o comprador, a renda aparece em sua contabilidade como o juro sobre o dinheiro investido na aquisição da terra, e em princípio não é diferente de investimentos semelhantes na dívida do governo, nas ações e nas quotas das empresas, na dívida do consumidor e assim por diante. $\bigcirc$ dinheiro investido é, em todos os casos, capital que rende juros. A terra se torna uma forma de capital fictício e o mercado imobiliário funciona simplesmente como um ramo particular - embora com algumas características especiais - da circulação do capital que rende juros. Nessas condições, a terra é tratada como um simples bem financeiro que é comprado e vendido segundo a renda que ele produz. Como todas essas formas de capital fictício, o que é negociado é um direito sobre as receitas futuras, o que significa um direito sobre os lucros do uso da terra ou, mais diretamente, um direito sobre o trabalho futuro. [Com efeito] a integração da posse da terra dentro da circulação do capital que rende juros pode abrir para o fluxo livre do capital, mas também a abre para o pleno jogo das contradições do capitalismo.

papel do Estado no processo de acumulação primitiva se dá, segundo a conhecida passagem de Marx no Livro II, pela dívida pública. A dívida pública "converte-se numa das alavancas mais poderosas da acumulação primitiva. Como uma varinha de condão, ela dota o dinheiro de capacidade criadora, transformando-o assim em capital [...]" (Marx, 1987, p. 872873). Na fase imperialista:

[...] os empréstimos externos desempenham papel extraordinário como meio de emancipação dos novos Estados capitalistas. $\bigcirc$ que existe de contraditório na fase imperialista se revela claramente nas oposições características do moderno sistema de empréstimos externos [...] os empréstimos são um meio extraordinário para abrir novas áreas de investimentos para o capital acumulado [e de ampliar a sua esfera de ação] (Luxemburg, 1984, p. 66).

Na concepção de David Harvey (2014, p. 111), o Estado se apresenta como a "entidade política" que opera, no nível das organizações institucionais, a realização da efetiva subordinação das "forças moleculares de acumulação do capital para preservar o padrão de assimetrias nas trocas mais vantajosas para os interesses capitalistas dominantes que trabalham nesse âmbito", ou seja, uma aparente razão universal do poder que opera em defesa de interesses privados da acumulação de capital. Contudo, o autor ressalta que a acumulação primitiva analisada por Marx constitui ainda hoje um vigoroso processo em curso e que tem um conjunto de características que permite elucidar as formas contemporâneas de acumulação por espoliação, "fortemente presentes na geografia histórica do capitalismo até os nossos dias [...] $\bigcirc$ sistema de crédito e o capital financeiro se tornaram [...] grandes trampolins de predação, fraude e roubo" (Harvey, 2014, p. 121-122). 


\section{Valorização do espaço e formação territorial do Brasil}

A história territorial do Brasil tem particularidades que podem ser identificadas e analisadas a partir da colonização portuguesa durante a fase dos acordos geopolíticos entre Portugal e Espanha na demarcação das fronteiras mediante os tratados dos séculos XVIII e XIX e, ulteriormente, pela efetivação da propriedade privada da terra a partir de meados do século XIX. A colonização, cujo móvel essencial é a violência, significa a destruição de todas as formas de sociabilidade preexistentes e de transformação mercantil da terra em fonte de produção agrícola, de renda e poder.

Embora o regime de sesmarias não configure uma propriedade privada stricto sensu, o direito de concessão de uso da terra e, consequentemente, o de exploração de seus recursos naturais implicam necessariamente a emergência das formas pretéritas e de separação e subordinação formal e real dos modos de vida originários e de seus meios de subsistência a um novo modo de organização do trabalho e da produção. As formas de subordinação formal e real que se concretizam no espaço, não sem resistência das formas tradicionais, produzem as condições necessárias à realização dos direitos dos sesmeiros na distribuição de terras e na aniquilação "de suas bocas inúteis".

$\bigcirc$ processo de efetivação da propriedade privada no Brasil deriva tanto de forças internas, como de forças externas ao espaço colonial (Moraes, 2000). Somente como criação do capital, a terra se torna condição de acumulação e fonte de renda, portanto, possibilidade de criação pela lógica do capital de uma esfera de investimentos e rendimentos futuros. Naturalmente, este artigo não visa apresentar e alinhavar toda a trama histórica da formação da propriedade privada no Brasil, mas permitir, dentro de seus limites, certo esclarecimento sobre a lógica de sua existência perante as necessidades de reprodução do capital.

De acordo com a análise de Martins (2010, p. 47), com a abolição da escravatura surge, como contraponto, a necessidade de garantia da propriedade privada da terra.

Combinavam-se de novo, sob outras condições históricas e, portanto, de outra forma, aparentemente invertidos, os elementos de sustentação da economia de tipo colonial. A renda, até então capitalizada no escravo, tornava-se renda territorial capitalizada. Se no regime sesmarial, o da terra livre, o trabalho tivera que ser cativo; num regime de trabalho livre a terra tinha que ser cativa. No Brasil, a renda territorial capitalizada não é essencialmente uma transfigurada herança feudal. Ela é engendrada no bojo da crise do trabalho escravo, como meio para garantir a sujeição do trabalho ao capital, como substituto da expropriação territorial do camponês que, no advento do capitalismo, criou a massa de deserdados apta a entrar no mercado de trabalho da nova sociedade. [Desse modo] a renda territorial surge da metamorfose da renda capitalizada na pessoa do escravo; surge, portanto, como forma de capital tributário do comércio e não do traficante, como aquisição do direito de exploração da força de trabalho, em oposição ao direito de propriedade sobre a pessoa do trabalhador.

A transição do trabalho escravo para o trabalho assalariado, apontada por Martins, só pôde ocorrer em virtude da criação das condições objetivas da separação entre trabalho e meios de produção e da efetivação da propriedade privada da terra e, desse modo, "garantir a sujeição do trabalho ao capital". 
De acordo com Moraes (2000, p. 272-273):

As diferentes formas que se reveste a coerção não devem enturvar a recorrência e centralidade dessa determinação [ou seja, o trabalho compulsório]. Portanto, o povoamento colonial foi na maior parte, um fluxo migratório forçado. Seja o servo, seja o escravo africano, seja o índio, todos pertencem a populações deslocadas compulsoriamente de seu habitat original e submetidas a novo ordenamento social e espacial, que as requalifica por mecanismos de exclusão como os impedimentos raciais e a seletividade territorial.

Entretanto, essas mudanças não ocorrem ao mesmo tempo e nem duram o mesmo que movimentos de transformação social. A sobreposição e os diferentes modos de interação desses processos sociais adquirem graus de complexidade crescente à medida que assumem formas também diferentes de participação no desenvolvimento das forças produtivas e das relações sociais de produção.

A transmutação das práticas sociais em ideologias atribui ao território a personificação da unidade entre Estado e sociedade de modo a engendrar, em sentido inteiramente abstrato, as formas hibridas de identidade nacional que garantem a coesão política e o exercício do poder da classe dominante. De acordo com Moraes (2000, p. 21), uma das características do Estado moderno é "o fato de ele possuir um espaço demarcado de exercício de poder", ou seja, o território é a base física da execução do poder. No entanto, o autor reconhece que a relação entre Estado e território é estabelecida a partir de um lento processo histórico que envolve aspectos políticos, jurídicos, econômicos e culturais e que resulta numa unidade: o país. A esse processo que substancia a relação sociedade-espaço, o autor conceitua como "formação territorial-estatal": "Em tal entendimento, o território emerge como uma totalidade para a geografia, um espaço dotado de uma historicidade própria, que corresponderia à espacialidade de uma dada formação econômica e social".

De acordo com Antonio Carlos Robert Moraes (2006, p. 42-43):

[...] as formações sociais constituídas no processo de colonização européia do Novo Mundo constituíram tentativas de estabelecer prolongamentos [...] das sociedades metropolitanas no além-mar [...]. Pode-se dizer que eles constituíram as repercussões latino-americanas das transformações na ordem política em curso nas metrópoles européias na época.

Com efeito, enfatiza o autor, a interpretação da geografia histórica da formação territorial capitalista "ancora-se na particularidade dos processos de valorização do espaço" e, dialeticamente, pode ser articulada a partir de "dois movimentos básicos: o da fixação geográfica do valor", que permite analisar as formas de "apropriação e produção dos espaços [...] e o da transferência geográfica do valor, impulsionador dos fluxos, logo dos circuitos de circulação em geral" (Moraes, 2006, p. 45).

Nesse sentido, o território é compreendido como "um resultado histórico do relacionamento da sociedade com o espaço, o qual só pode ser desvendado por meio do estudo de sua gênese e desenvolvimento" (Moraes, 2006, p. 21). Assim, do ponto de vista espacial, a 
construção territorial consiste num processo cumulativo que obedece a uma lógica societária vigente e em que se articulam formas sociais muitas vezes diacrônicas ou descontínuas, mas específicas de cada formação socioeconômica e espacial. $\bigcirc$ autor reconhece ainda que a formação territorial compreende formas tanto materiais quanto simbólicas, que unificam e norteiam os diversos aspectos envolvidos num território (Moraes, 2005, p. 58).

$\bigcirc$ território material é referência para formas de consciência e representação, cujos discursos retroagem no processo de produção material do espaço, com o imaginário territorial comandando a apropriação e exploração dos lugares. $\bigcirc$ território é, concomitantemente, uma construção militar (um resultado da conquista espacial, que tem de ser reiterada sempre que contestada) e uma construção política (como área de exercício de um poder soberano), mas também uma construção econômica (como suporte de estruturas e atividades produtivas como um mercado) e uma construção jurídica (que tem de ser legitimada em fóruns adequados de relacionamento internacional), e ainda uma construção ideológica (que fundamenta uma identidade social de base espacial e uma psicologia coletiva).

Sobre a aproximação da Geografia com a História, que retoma os processos sociais que resultam no ordenamento dos espaços e, portanto, resgata as dimensões econômicas, políticas e culturais que concorrem para a formação do território, Moraes (2005, p. 61) argumenta que permite "conceber a Geografia como uma História Territorial".

\section{Considerações finais}

Os apontamentos, os comentários e as tentativas de interpretação que apresentamos neste artigo têm o intuito de trazer, a partir dos estudos de Marx sobre propriedade privada, trabalho assalariado, produção de mais-valor, acumulação de capital etc., as categorias marxianas para a análise do processo histórico de valorização capitalista do espaço, em particular, a formação territorial no Brasil na segunda metade do século XIX.

As ricas contribuições de Milton Santos acerca da relação entre espaço, produção e valor, as importantes reflexões de Antonio Carlos Robert de Moraes sobre a historicidade da formação territorial e, igualmente, as análises de David Harvey em torno da acumulação por espoliação e da financeirização do território constituem-se bases teóricas para a interpretação do espaço-valor, ou espaço-mercadoria, cuja forma de espacialização, em sua metamorfose antitética, produz territórios fetichizados e capital fictício.

Quanto à gênese do capital, vimos que as práticas econômicas que engendram a chamada acumulação primitiva preservam até hoje sua lógica interna de separação entre as condições objetivas de produção e os produtores diretos, mediante o processo histórico de universalização da propriedade privada e de seu pressuposto seminal, o trabalho assalariado.

O processo de valorização capitalista do espaço e a formação territorial no Brasil encontram suas categorias fundantes na transição do trabalho escravo para o trabalho assalariado e, ao mesmo tempo, na efetivação da propriedade privada como condição de "sujeição do trabatho ao capital". A análise histórica dessas categorias fundamentadas na teoria marxista do valor 
é uma possibilidade de articular os movimentos de fixação e transferência de valor e, com mais profundidade, conceituar o espaço como mercadoria subsumida às contradições inerentes à reprodução social do capital e à valorização do valor.

Deve-se ressaltar ainda que há diferença entre a análise de Harvey da relação território-financeirização e a que procuramos desenvolver ao longo deste artigo. Para Harvey, apoiado na concepção de longos ciclos econômicos, de Giovanni Arrighi, existe uma contínua geografia histórica do capitalismo, que surge com a ascensão de Veneza e Gênova, passa pela Holanda, segue para a Inglaterra e, finalmente, desemboca no imperialismo estadunidense do século XX.

De acordo com Ellen Wood (2014, p. 129), a deficiência dessa argumentação é não apresentar as especificidades do capitalismo, com sua lógica sistêmica, em seu processo de formação e mundialização: "Na visão de Harvey, o processo histórico é em grande parte ilusório". Sua interpretação da acumulação primitiva não dá "nenhuma explicação sobre as origens do capitalismo e que não há nenhum processo de transformação histórica do não capitalismo para o capitalismo, pois Harvey dá o capitalismo mais ou menos como certo".

Vale notar também que a concepção de Harvey sobre a financeirização e a acumulação por espoliação não dá uma explicação satisfatória à lógica intrínseca da reprodução do capital no processo de valorização do espaço como condição de acumulação ampliada. $\bigcirc$ papel do Estado territorial que Harvey defende é muito importante para desvelar o caráter geopolítico do mercado global como uma constelação de Estados independentes, mas pouco esclarece sobre o modo de alienação do trabalho como essência da propriedade privada e a dialética do movimento histórico que transforma a terra em valor de troca, fundo de renda, garantia de crédito, capital fictício, enfim, em mercadoria.

Finalmente, uma palavra sobre o tom irônico do título do artigo. Quisemos expressar não só o peculiar status quo do discreto charme da geografia burguesa na ocultação de seu "pecado original", mas também o caráter fetichista de seus conceitos e de suas interpretações geográficas acerca dos processos históricos da valorização capitalista do e no espaço. Em suma, o problema de que procuramos tratar é acompanhado de uma série de polêmicas teóricas em torno do desenvolvimento do capitalismo e de sua específica geografia histórica. Os argumentos dos autores que apresentamos estão longe de caracterizá-los inteiramente frente às formas de interpretação acerca da valorização capitalista do espaço. $\bigcirc$ objetivo era apenas apresentar notas e apontamentos para uma análise histórica e dialética da produção do espaço geográfico como mercadoria específica do modo capitalista de produção.

\section{Referências}

BENJAMIN, W. O capitalismo como religião. Trad. Nélio Schneider. São Paulo: Boitempo, 2013.

CHAUÍ, M. Seminários: o nacional e o popular na cultura brasileira. São Paulo: Brasiliense, 1984.

COTRIM, I. Karl Marx: a determinação ontonegativa originária do valor. São Paulo: Alameda, 2011. 
HARVEY, D. O novo imperialismo. Trad. Adail Sobral; Maria Stela Gonçalves. São Paulo: Loyola, 2014.

HARVEY, D. Os limites do capital. Trad. Magda Lopes. São Paulo: Boitempo, 2013.

HARVEY, D. A produção capitalista do espaço. Trad. Carlos Szlak. São Paulo: Annablume, 2005.

LÊNIN, V. I. Imperialismo, fase superior do capitalismo. São Paulo: Global, 1987.

LUXEMBURG, R. A acumulação do capital. Trad. Marijane Vieira Lisboa; Otto Erich Walter Maas. São Paulo: Abril Cultural, 1984. v. 2.

MARTINS, J. S. O cativeiro da terra. São Paulo: Contexto, 2010.

MARX, K. Cadernos de Paris e manuscritos econômico-filosóficos de 1844. Trad. José Paulo Netto; Maria Antónia Pacheco. São Paulo: Expressão Popular, 2015.

MARX, K. O capital. Trad. Rubens Enderle. São Paulo: Boitempo, 2013. v. 1.

MARX, K. Grundrisse. Trad. Mario Duayer; Nélio Schneider. São Paulo: Boitempo, 2011.

MARX, K. Formações econômicas pré-capitalistas. Trad. João Maia. São Paulo: Paz e Terra, 1991.

MARX, K. O capital. Trad. Reginaldo Sant’ anna. São Paulo: Difel, 1987. v. 2.

MARX, K. Manuscritos econômico-filosóficos de 1844. Trad. José Arthur Giannotti. São Paulo: Abril Cultural, 1974.

MARX, K. A origem do capital. Trad. Walter Maia. São Paulo: Fulgor, 1964.

MORAES, A. C. R. A afirmação da territorialidade estatal no Brasil: uma introdução. In: LEMOS, A. I.; SILVEIRA, M. L.; ARROYO, M. (Org.). Questões territoriais na América Latina. Buenos Aires: Clacso/São Paulo: Edusp, 2006. p. 41-54.

MORAES, A. C. R. Território e história do Brasil. São Paulo: Annablume, 2005.

MORAES, A. C. R. Bases da formação territorial do Brasil: o território colonial brasileiro no "longo" século XVI. São Paulo: Hucitec, 2000.

MORAES, A. C. R. Geografia crítica: a valorização do espaço. São Paulo: Hucitec, 1984.

ROSDOLSKY, R. Gênese e estrutura de $\mathbf{O}$ capital de Karl Marx. Trad. César Benjamin. Rio de Janeiro: Ed. UERJ/Contraponto, 2001.

SANTOS, M. Espaço e método. São Paulo: Nobel, 1992.

WOOD, E. M. O império do capital. Trad. Paulo C. Castanheira. São Paulo: Boitempo, 2014. 